\title{
ГЕОГРАФИЯ
}

\section{Суточная и сезонная динамика температуры поверхности города Волгограда}

\author{
О.Ю. Кошелева ${ }^{1}$, С.С. Шинкаренко $0^{1,2}$, О.А. Гордиенко ${ }^{1,2}$, \\ А.А. Дубачева ${ }^{3}$, Р. С. Омаров ${ }^{1,2}$ \\ ${ }^{1}$ ФНЦ агроэкологии РАН, Российская Федерация \\ (400062, г. Волгоград, пр-т Университетский, 97) \\ ${ }^{2}$ Волгоградский государственный университет, Российская Федерация \\ (400062, г. Волгоград, пр-т Университетский, 100) \\ ${ }^{3}$ Российский информационно-аналитический и научно-исследовательский \\ водохозяйственный центр, Российская Федерачия \\ (400001, г. Волгоград, ул. Канунникова, 6/1)
}

\begin{abstract}
Аннотация: Цель - установить особенности суточной и сезонной динамики температуры поверхности в городе Волгограде (на примере 2018 года, «типового» по климатическим характеристикам) и выяснить, зависит ли её сезонный ход от особенностей подстилающей поверхности городской территории.

Maтериалы и методbl. Для выбора года исследования был проанализирован 20-летний ход температур воздуха в Волгограде, а также учитывалось наличие непрерывных данных о температурах подстилающей поверхности. Определение температуры городской поверхности проводилось путем обработки снимков теплого полугодия информационного продукта MOD11A2 (8-ми дневные растровые композиты дневной и ночной температур разрешением около 1 км). Геоинформационная обработка снимков осуществлялась в программе QGIS. По данным Global Land Cover (GLC) определены основные типы подстилающей поверхности на территории Волгограда.

Результаты и обсуждение. Доля запечатанных поверхностей составляет 38,2%. Составлена карта среднегодовых температур поверхности в Волгограде, отражающая основные особенности пространственного распределения положительных и отрицательных тепловых аномалий. Установлено, что сезонный ход среднесуточных, дневных и ночных температур подстилающей поверхности и приземного слоя воздуха в Волгограде представляет собой обращенную ветвями вниз параболу с максимумом, приходящимся на период 26 июня - 6 июля. Ход среднесуточных температур воздуха повторяет сезонный ход температуры поверхности города $(\mathrm{r}=0,99)$.

Bblводbl. Картографирование на основе данных MODIS с разрешением 1 км позволяет выявить пространственное распространение крупных положительных и отрицательных аномалий на территории города и его окрестностей. Выявлена значительная вариабельность значений среднесуточной температуры подстилающей поверхности в районах с высокой долей водных объектов, водно-болотных угодий и низкой степенью запечатанности почвенного покрова.

Ключевые слова: поверхностный остров тепла, MODIS, Волгоград, среднесуточная температура, дневная температура городской поверхности, ночная температура городской поверхности, запечатанные поверхности.

Источник финансирования: Исследование выполнено при финансовой поддержке Российского фонда фундаментальных исследований и Администрации Волгоградской области в рамках научного проекта № 19-45-343001.

Для цитирования: Кошелева О. Ю., Шинкаренко С. С., Гордиенко О. А., Дубачева А. А., Омаров Р. С. Суточная и сезонная динамика температуры поверхности города Волгограда // Вестник Воронежского государственного университета. Серия: География. Геоэкология, 2021, № 1, с. 14-24. DOI: https://doi.org/10.17308/geo.2021.1/3252
\end{abstract}

(C) Кошелева О. Ю., Шинкаренко С. С., Гордиенко О. А., Дубачева А. А., Омаров Р. С., 2021 $\triangle$ Кошелева Ольга Юрьевна, e-mail: olya_ber@mail.ru

Контент доступен под лицензией Creative Commons Attribution 4.0 License. 


\section{ВВЕДЕНИЕ}

В современных условиях интенсивные процессы развития инфраструктуры крупных городов и активное загрязнение атмосферного воздуха приводят к формированию в них особого климатического режима - городского «острова тепла» $[2,4]$.

Активные исследования городов с использованием данных тепловых спутниковых съемок сосредоточены на особенностях сезонной динамики тепловых аномалий, картировании перегрева поверхности, разработке методик оценки интенсивности городского «острова тепла» с учетом характеристик городского ландшафта - плотности застройки, доли растительного покрова, интенсивности автотранспортной нагрузки $[1,4,7,11]$. Все авторы сходятся во мнении, что климатические условия города определяются его географическим положением и ландшафтной спецификой, так как радиационный баланс подстилающей поверхности в значительной степени зависит от интегрального альбедо всех искусственных и естественных поверхностей урбанизированных пространств.

Цель данного исследования - установить особенности суточной и сезонной динамики температуры поверхности крупного города и выяснить, зависит ли её сезонный ход от особенностей подстилающей поверхности городской территории.

\section{ОБЪЕКТ ИССЛЕДОВАНИЯ}

В качестве объекта исследования выбран Волгоград, являющийся одним из крупнейших городов в юго-восточной части Европейской России. Город расположен в сухостепной зоне на значительном удалении от морей, что обусловило умеренно-континентальный тип климата на его территории. Волгоград находится в начале списка городов с максимальными летними температурами. В летний сезон здесь господствуют воздушные массы из Атлантики и тогда температура воздуха держится на отметке $+20 \ldots+25^{\circ} \mathrm{C}$, а при вторжении раскалённого сухого воздуха из степей Казахстана температуpa повышается до $+35 \ldots+40^{\circ} \mathrm{C}$. Периоды сильной жары доставляют большие неудобства жителям города и народному хозяйству, что усугубляется общим загрязнением атмосферного воздуха от работы промышленных предприятий и автотранспорта.

Специфика географического положения Волгограда состоит еще и в том, что градообразующим элементом выступает река Волга. Семь из восьми административных районов города выходят к реке. С запада к городской черте подступают крутые склоны Приволжской возвышенности, переходящие в районе Волго-Донского судоходного канала в Ергени и Сарпинскую низменность. В 2008 году в административные границы города был включен остров Сарпинский, где преобладают пойменные ландшафты, отмечается ежегодное половодье [12]. Если не считать пойменных лесов острова Сарпинский, то для города Волгограда характерна низкая обеспеченность лесными насаждениями - 11-13 м²/чел. из рекомендованных для крупных городов 24,6 $\mathrm{m}^{2} /$ чел. [3].

\section{МАТЕРИАЛЫ И МЕТОДЫ ИССЛЕДОВАНИЙ}

Для определения репрезентативного по температурным показателям года проанализирован 20-летний (с 1999 по 2018) ход температуры воздуха в Волгограде по данным метеостанции «Волгоград» [13]. Такой временной отрезок был выбран с учетом непрерывных данных о температурах подстилающей поверхности (данные MODIS доступны с 2000-го года). По значениям среднегодовой температуры практически «типовым» оказался 2018 год: среднегодовая температура составила $8,9^{\circ} \mathrm{C}$ при норме $8,8^{\circ}$ (рис. 1 ).

Определение температуры городской поверхности за 2018 год (LST - Land Surface Temperature) основано на обработке информационного продукта MOD11A2 [16], представляющего собой 8-ми дневные растровые композиты дневной и ночной температур с разрешением около 1 км. Преимуществом данных MODIS по сравнению с продуктами более высокого пространственного разрешения является высокое временное разрешение, позволяющее охватить практически весь год без разрывов. В то время как данные Landsat могут быть получены с интервалом в 16 дней при безоблачной погоде в момент съемки.

Исходные данные в формате hdf и синусоидальной проекции были сконвертированы и перепроецированы в общеземную географическую систему WGS84 с помощью утилиты Modis reprojection tool. Для перевода в градусы Цельсия значения растров умножаются на 0,02 (при этом получаются значения температуры в Кельвинах) и из полученных значений вычитается 273,15.

В выборке снимков MODIS преобладают снимки теплого полугодия (с марта по ноябрь). Согласно исследованиям [17], зимой тепловой остров не наблюдается, а появляется весной и последовательно развивается к лету и осени. К тому же в зимнее время безоблачные дни бывают намного реже, что усложняет процедуру отбора снимков с покрытием облаками в допустимых пределах $(<10-20 \%)$. Безусловно, это сказывается на среднегодовых значениях температуры поверх- 


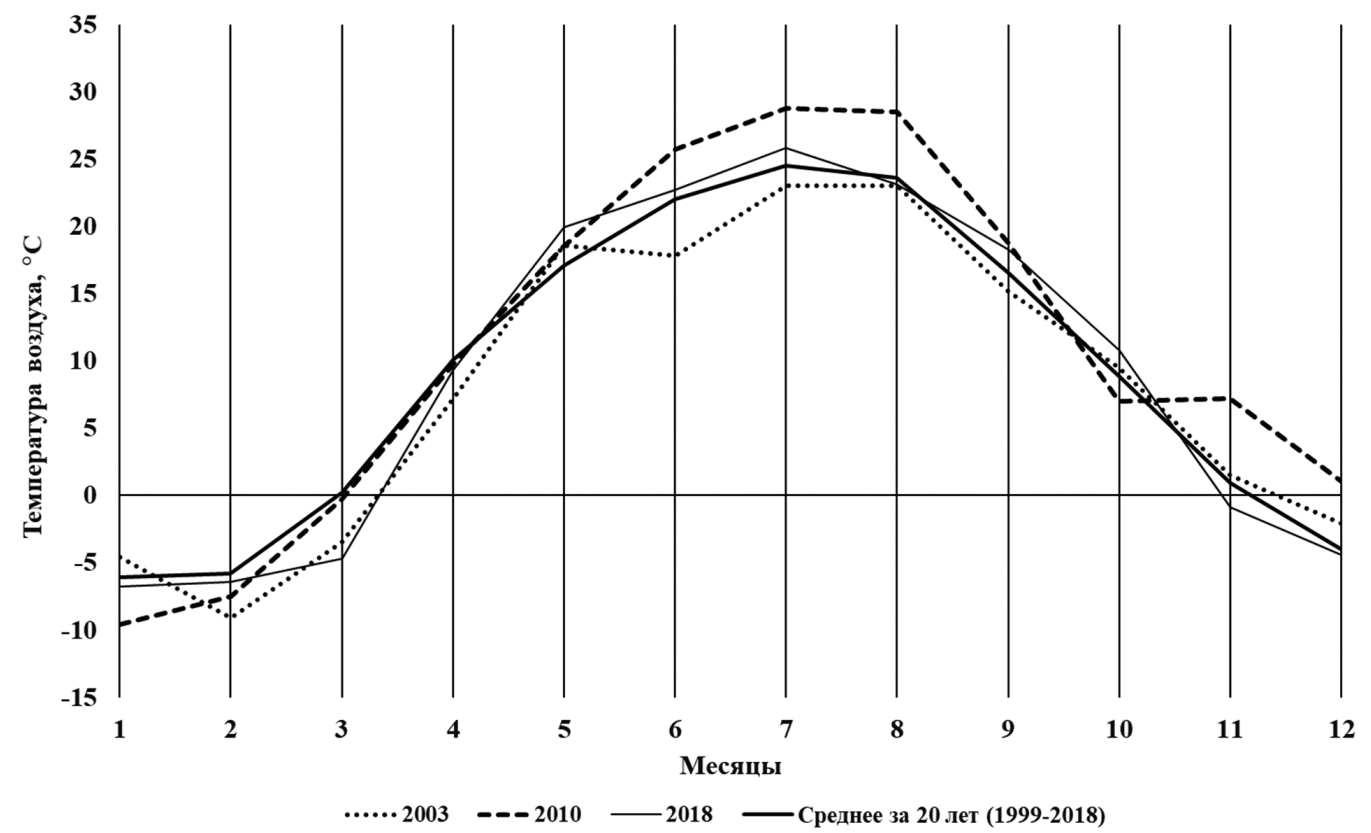

Puc. 1. Сопоставление хода температуры воздуха в годы с максимальной (2010), минимальной (2003) и средней (2018) среднегодовыми температурами (за период 1999-2018 гг. по данным метеостанции «Волгоград»)

[Fig. 1. Comparison of air temperature variations in years with maximum (2010), minimum (2003) and average (2018) long-term average temperatures (for the period 1999-2018 according to the data of the Volgograd meteorological station)]

ности, однако при анализе сезонного хода температуры этот факт не столь критичен.

Геоинформационная обработка снимков осуществлялась в программе QGIS: определялись средние значения температуры городской поверхности (в калькуляторе растров QGIS), строились сеточные карты температуры поверхности, где каждой ячейке соответствовал пиксель MODIS. Типы подстилающей поверхности приведены по данным Global land cover (GLC) разрешением 30 м [15]. Геоинформационный слой типов подстилающей поверхности был пересечен регулярной сеткой, после чего для каждой ячейки подсчитаны площади всех типов поверхностей, входящих в нее. Аналогично были рассчитаны площади для районов города по слою-маске с их границами. Картографические материалы представлены в проекции UTM (зона 38N), система координат WGS 84.

Обозначение временных периодов на графиках хода температур подстилающей поверхности и воздуха дается согласно «Таблице порядковых номеров дней в году (не високосном)».

\section{РЕЗУЛЬТАТЫ И ИХ ОБСУЖДЕНИЕ}

В очень обобщенном виде, температура подстилающей поверхности определяется приходом прямой и рассеянной солнечной радиации, а температура приземного слоя воздуха - температурой подстилающей поверхности. Как известно, нижние слои атмосферы нагреваются от поверхности суши и воды. Механизм возникновения эффекта «теплового острова» над городом обусловлен теми же самыми природными процессами, однако здесь существенную роль начинают играть поверхности, перекрытые слоем плотного техногенного материала (запечатанные) [9]. Запечатанность, как вид антропогенного воздействия, характеризующийся наличием на поверхности почв или грунтов слоя плотного техногенного материала, изменяет характер теплообмена почвы с атмосферой: происходит накапливание тепла на территории города за счет значительного снижения альбедо асфальтобетонных покрытий по сравнению с естественными ландшафтами [5].

В административных границах Волгограда доля запечатанных поверхностей, по данным Global land cover, составляет 38,2\%. По административным районам эта цифра варьирует от 17-20\% до 90-92 \% (таблица). Самые низкие значения запечатанности поверхности имеют районы, где сохраняются большие площади рекреационного и сельскохозяйственного назначения и крупные пустыри - Кировский и Советский $[3,6]$.

При анализе хода годовых температур для Волгограда следует учитывать наличие такого крупного водного объекта как река Волга. Водная 
поверхность, обладая большой теплоемкостью и высокой отражающей способностью, формирует зону влияния, ширина которой зависит от сезона года и размера водного зеркала. Мягков М. С. с соавторами [10] указывает, что зона влияния Москвы-реки достигает 100 м, при этом зона максимального снижения температуры (до $1,8^{\circ} \mathrm{C}$ ) составляет 50 м. Литвинов Д. В. [8] считает, что для городов Поволжья ширина зоны влияния реки в зависимости от периода года и состояния облачности может варьировать в пределах 200-900 м от уреза воды. Для территории Волгограда наибольшее влияние водных поверхностей на температуру отмечено в апреле-июне (значения коэффициентов корреляции $\mathrm{r}=0,4-0,6$ при уровне значимости а $<0,001)$. Это связано с периодом половодья.

Внутри города можно выделить два типа тепловых аномалий (положительные и отрицательные) и два типа объектов, их формирующих [4]. Объекты промышленности, общественно-деловая и многоэтажная жилая застройка, особенно слабоозелененные районы новостроек, крупные склады и торговые центры формируют положительные тепловые аномалии. Напротив, крупные зелёные массивы и акватории образуют крупные «острова прохлады» в тёплый сезон года.

Пространственное разрешение снимков MODIS (1 км) не позволяет выделить единичные объекты, оказывающие то или иное влияние на тепловую структуру города. Однако, картографирование среднегодовых температур поверхности в Волгограде и его окрестностях позволяет определить основные особенности пространственного распределения положительных и отрицательных тепловых аномалий.

Жилая и промышленная застройка, протянувшиеся в 2-3-километровой зоне вдоль берега Волги, являются наиболее «тёплыми» - среднегодовая температура поверхности здесь достигает 20$21^{\circ} \mathrm{C}$. Лесные массивы, пустыри и пастбища формируют по окраинам города более «прохладные» ареалы $\left(18-19^{\circ} \mathrm{C}\right)$. Водные объекты и водно-бо-

Распределение различных типов подстилающей поверхности

Таблица по районам города Волгограда, в гектарах

[Table. Distribution of different types of land cover by districts of the Volgograd City, hectares]

\begin{tabular}{|c|c|c|c|c|c|c|c|}
\hline \multirow{2}{*}{ Район / District } & \multicolumn{6}{|c|}{ Типы подстилающей поверхности / Land cover type } & \multirow{2}{*}{$\begin{array}{c}\text { ИТОГО } \\
\text { по району } \\
\text { TOTAL }\end{array}$} \\
\hline & 1 & 2 & 3 & 4 & 5 & 6 & \\
\hline $\begin{array}{l}\text { Tракторозаводский / } \\
\text { Traktorozavodsky }\end{array}$ & 1116,7 & 140,8 & 800,1 & - & 757,7 & 4221,7 & 7037,1 \\
\hline $\begin{array}{l}\text { Краснооктябрьский / } \\
\text { Krasnooktyabrsky }\end{array}$ & 3,4 & 0,2 & 4,0 & - & 308,6 & 3551,5 & 3867,7 \\
\hline $\begin{array}{l}\text { Центральный / } \\
\text { Central }\end{array}$ & - & - & 63,6 & - & 314,5 & 1054,5 & 1432,6 \\
\hline $\begin{array}{l}\text { Дзержинский / } \\
\text { Dzerzhinsky }\end{array}$ & 256,2 & 269,0 & 1686,4 & - & 17,0 & 5301,2 & 7529,8 \\
\hline $\begin{array}{l}\text { Ворошиловский / } \\
\text { Voroshilovsky }\end{array}$ & - & 57,6 & 733,5 & - & 176,9 & 1987,1 & 2955,1 \\
\hline $\begin{array}{l}\text { Советский / } \\
\text { Sovietsky }\end{array}$ & 16738,8 & 552,6 & 3920,3 & 29,4 & 350,4 & 6097,5 & 27689,1 \\
\hline $\begin{array}{l}\text { Кировский / } \\
\text { Kirovsky }\end{array}$ & 1517,0 & 223,0 & 2677,6 & 10458,1 & 2986,0 & 3858,7 & 21720,4 \\
\hline $\begin{array}{l}\text { Красноармейский / } \\
\text { Krasnoarmeisky }\end{array}$ & 1372,1 & 656,8 & 2734,2 & 504,4 & 1591,6 & 6656,5 & 13515,7 \\
\hline $\begin{array}{l}\text { ИТОГО по типу ПП / } \\
\text { TOТАL }\end{array}$ & 21004,2 & 1900,0 & 12619,8 & 10992,0 & 6502,8 & 32728,8 & 85747,5 \\
\hline
\end{tabular}

Примечание: 1 - памня, 2 -леса, 3 - пастбища и пустыри, 4-водно-болотные угодья, 5 - водные объекты, 6 - запечатанные поверхности.

[Note: 1 -cropland, 2 -forests, 3 -grassland, 4 -wetland, 5 -water bodies, 6 - soil sealing]. 
лотные угодья самые «холодные» - среднегодовые температуры их поверхности составляют 12$16^{\circ} \mathrm{C}$

Анализ сезонной динамики среднесуточной температуры городской поверхности подтвердил известную закономерность о том, что температура воздуха меняется вслед за температурой земной поверхности [14]. Практически на всем протяжении теплого периода года среднесуточная температура поверхности выше среднесуточной температуры воздуха (рис. 2a).
При этом разложение на дневные и ночные температуры дает разную картину. В 2018 году, начиная с 10 апреля, когда увеличивается приход прямой солнечной радиации, дневная температура поверхности стала стабильно выше температуры воздуха. В весенний период разница составила $3-7^{\circ} \mathrm{C}$, достигнув $13-15^{\circ} \mathrm{C}$ в летние месяцы (рис. 2б).

Ночью солнечная радиация отсутствует, поэтому подстилающая поверхность, в основном, только излучает тепло, постепенно охлаждаясь. Вместе с земной поверхностью охлаждается и

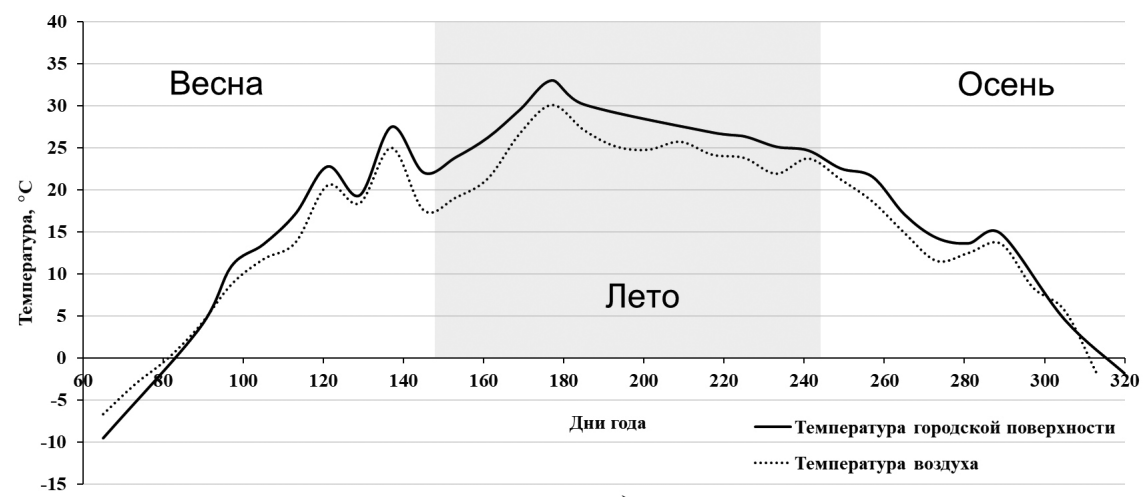

a)

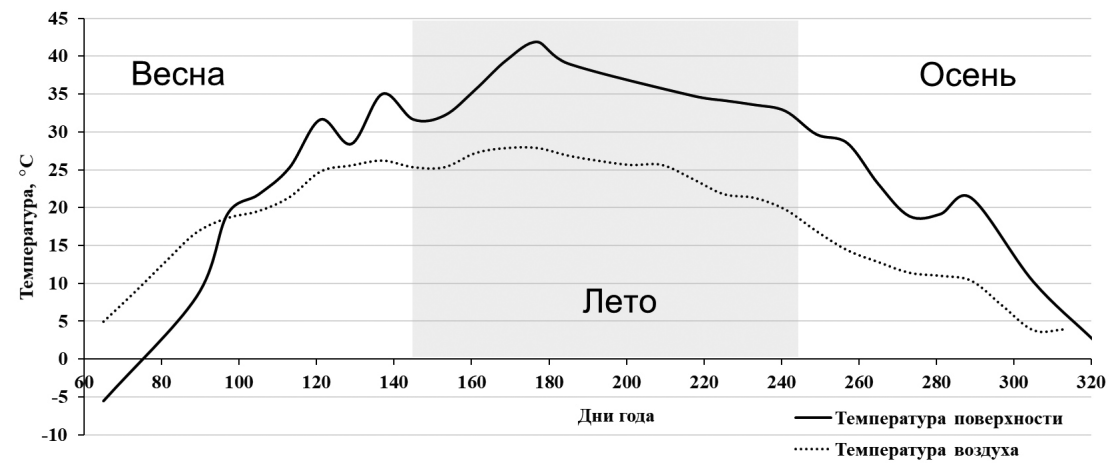

б)

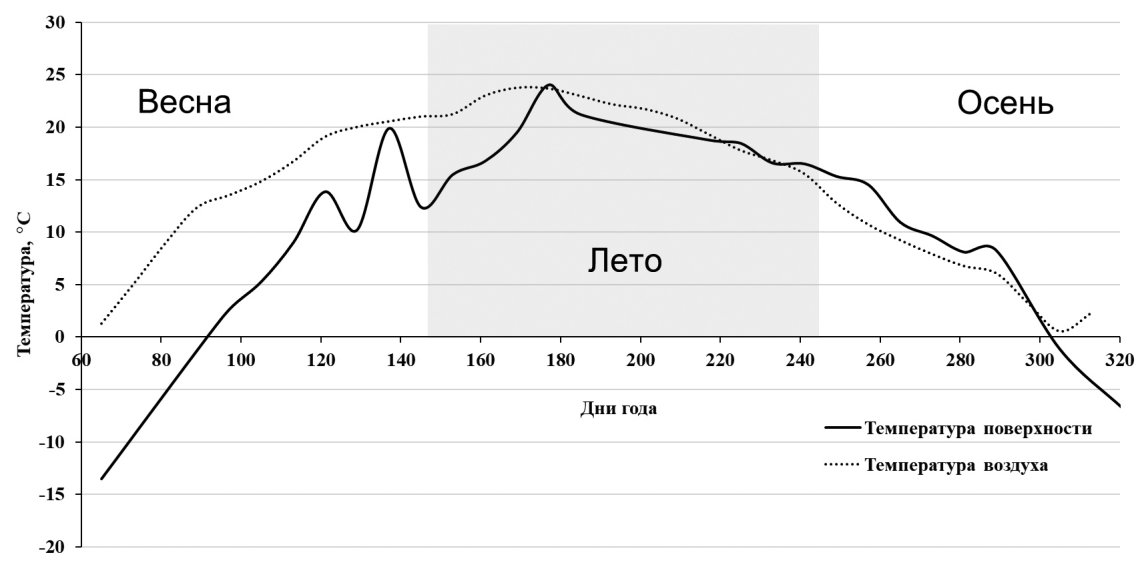

B)

Puc. 2. Сезонная динамика среднесуточных (а), дневных (б) и ночных (в) температур городской поверхности и воздуха в Волгограде в 2018 году

[Fig. 2. Seasonal dynamics of average daily (a), daytime (b) and nighttime (c) temperatures of the urban surface and air in Volgograd in 2018] 
нижний слой воздуха. На графике это отражается в виде некоторого «запаздывания» кривой температуры воздуха: убыль солнечной радиации восполняется излучением тепла с подстилающей поверхности (рис. 2в). Однако такой, достаточно правильный, ход температуры воздуха проявляется лишь в условиях устойчивой ясной погоды [14]. В конце лета-начале осени с общим понижением температуры поверхности, изменением облачности и увеличением количества осадков средняя ночная температура воздуха оказывается ниже температуры подстилающей поверхности.

По административным районам города ход среднесуточной температуры поверхности также близок к ходу температуры воздуха (рис. 3а). Значительных различий между районами не выявлено, однако наименьшие среднесуточные температуры поверхности отмечены в Кировском районе, а наибольшие - в Дзержинском. В состав Кировского района входит остров Сарпинский, а это около 12 тыс. гектаров лесов, ериков и проток, водно-болотных угодий, практически полное отсутствие запечатанных поверхностей, а также охлаждающее воздействие обширной акватории Волги. Дзержинский же район является самым удаленным от Волги и не имеет к ней доступа.

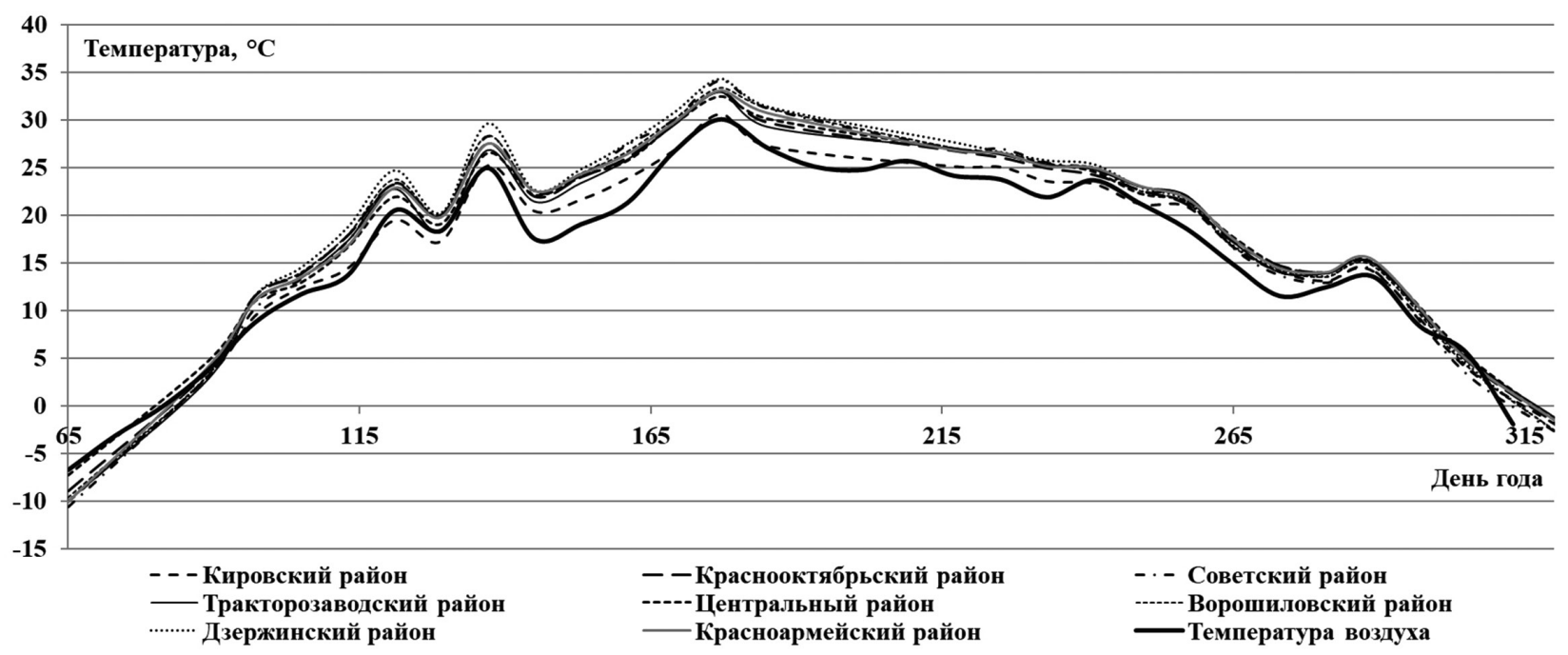

a)

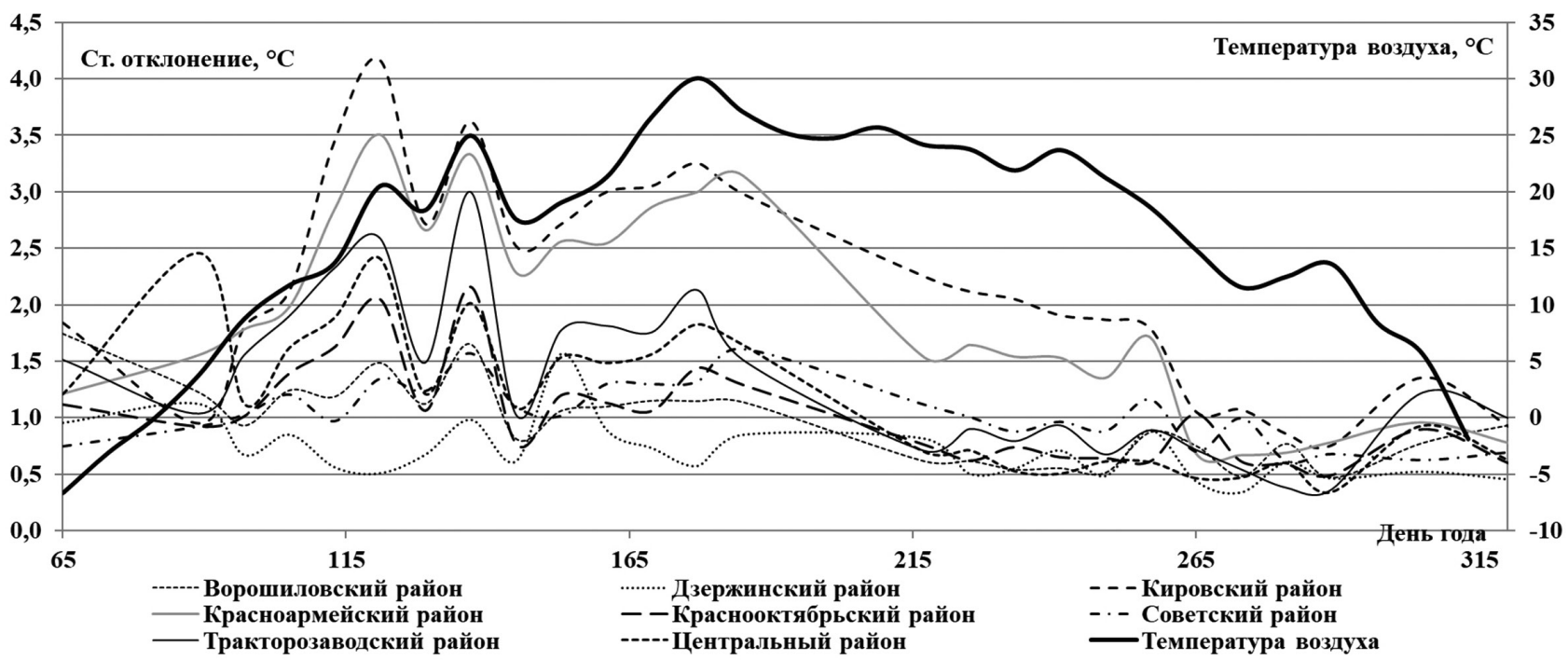

б)

Puc. 3. Динамика среднесуточных температур (а) и стандартного отклонения среднесуточных температур (б) в границах административных районов Волгограда в 2018 году

[Fig. 3. Dynamics of average daily temperatures (a) and standard deviations of average daily tem-peratures (b) within the boundaries of the administrative districts of Volgograd in 2018]

Вестник ВГУ, Серия: География. Геоэкология, 2021, № 1, 14-24 
Доля запечатанности поверхности в данном районе одна из самых высоких в городе, что обусловлено большим количеством застройки, промышленных предприятий, складских зон и крупных транспортных развязок.

Вместе с тем, несмотря на то, что ход среднесуточных температур в целом повторяет сезонный ход температуры поверхности города $(\mathrm{r}=0,99)$, внутри административных районов наблюдается существенный разброс значений температуры поверхности, обусловленный различным соотношением в них типов подстилающей поверхности с неоднородными теплофизическими свойствами (рис. 3б). В целом, по районам, наибольшие колебания температурных амплитуд отмечаются весной (апрель-май), что, по-видимому, связано с началом активной вегетации растительности и периодом половодья. Эти природные процессы на границе холодного и теплого периодов года значительно меняют соотношение типов подстилающей поверхности, увеличивая площадь озелененных пространств и водных объектов. Наибольший разброс значений среднесуточных температур поверхности отмечен в Кировском районе, а наименьшая вариабельность значений среднесуточных температур наблюдается в Дзержинском.

В остальных районах города стандартный сезонный ход среднесуточных температур подстилающей поверхности, обусловленный умеренным влиянием Волги и типичным пространственным соотнесением зон застройки, плотность которой постепенно снижается при удалении от реки, переходя в дачные массивы, защитный зеленый пояс и земли сельскохозяйственного и рекреационного использования.

Таким образом, изучение по данным снимков MODIS тепловой структуры города Волгограда дает возможность получить данные, актуальные для регионального территориального планирования с целью регулирования неблагоприятных эффектов «теплового острова» в летнее время путем обеспечения оптимального соотношения различных функциональных зон в городе, а также в каждом административном районе.

\section{ВЫВОДЫ}

1. Картографирование на основе 8-ми дневных растровых композитов дневной и ночной температур MOD11A2 с разрешением 1 км позволяет выявить пространственное распространение крупных положительных и отрицательных аномалий на территории крупного города и его окрестностей.
2. На изучаемой территории наблюдается хорошо выраженный сезонный ход среднесуточных, дневных и ночных температур подстилающей поверхности и приземного слоя воздуха, представляющий собой обращенную ветвями вниз параболу с максимумом, приходящимся на период 26 июня - 6 июля.

3. Влияние на сезонный ход среднесуточных температур поверхности, а соответственно и воздуха, различных типов подстилающей поверхности становится заметным только после анализа сезонной динамики температурных показателей в территориальном разрезе (по отдельным районам города). Установлена значительная вариабельность значений среднесуточной температуры подстилающей поверхности в районе с высокой долей водных объектов, водно-болотных угодий и низкой степенью запечатанности почвенного покрова. Особенно заметен разброс температурных значений в период половодья (апрель-май). Наиболее стабильный ход среднесуточной температуры поверхности установлен для самого удаленного от Волги района, для которого влияние такой крупной акватории сведено практически к минимуму и к тому же здесь существуют максимальные площади запечатанности почв.

\section{СПИСОК ЛИТЕРАТУРЫ}

1. Балдина Е.А., Грищенко М.Ю., Константинов П.И., Варенцов М.И. Исследование городских островов тепла с помощью данных дистанционного зондирования в инфракрасном тепловом диапазоне // Земля из космоса - наиболее эффективные решения, 2015, специальный выпуск, с. 38-42.

2. Брусова Н.Е., Кузнецова И.Н., Нахаев М. И. Тепловое возмущение мегаполиса на фоне региональной неоднородности поля приземной температуры // Tpyды Гидрометиентра России, 2017, вып. 365, с. 22-34.

3. Гордиенко О.А., Манаенков И.В., Холоденко А.В., Иванцова Е.А. Картографирование и оценка степени запечатанности почв города Волгограда // Почвоведение, 2019, № 11, с. 1383-1392. DOI: http://doi. org/10.1134/S0032180X19110054

4. Грищенко М.Ю., Калитка Л.С. Изучение сезонной изменчивости теплового поля Краснодара по космическим снимкам со спутника Landsat 8 // Mameриаль Международная конферениял «ИнтерКарто. ИнтерГИС. Геоинформационное обеспечение устойчивого развития территорий». Москва, 2019, т. 25, ч. 2, c. 101-111. DOI: http://doi.org/10.35595/2414-91792019-2-25-101-111

5. Ермакова Е.В., Мартыненко И.А. Оценка влияния запечатанности поверхности почвенного покрова на распределение температуры поверхности в условиях города на примере юго-восточного округа г. Москвы // Вестник Оренбургского государственного университета, 2011, № 12 (131), с. 68-70. 
6. Кошелева О. Ю. Оценка запечатанности почвенного покрова города Волгограда // Вестник Воронежского государственного университета. Серия: География. Геоэкология, 2019, №1, c. 12-18. DOI: https://doi. org/10.17308/geo.2019.1/2280

7. Крицук С. Г., Горный В.И., Латыпов И.Ш., Павловский А.А., Тронин А.А. Спутниковое картирование риска перегрева поверхности городской среды (на примере Санкт-Петербурга) // Современные проблемы дистанционного зондирования Земли из космоса, 2019, т. 16, № 5, с. 34-44. DOI: http://doi.org/10.21046/20707401-2019-16-5-34-44

8. Литвинов Д.В. Принципы зонирования прибрежных территорий в зависимости от планировочной структуры города (на примере городов Поволжья) // Вестник Самарского государственного архитектурно-строительного университета. Градостроительство и архитектура, 2011, № 3, с. 32-34. DOI: http://doi. org/10.17673/Vestnik.2011.03.8

9. Мировая реферативная база почвенных ресурсов 2014. Международная система почвенной классификачии для диагностики почв и создания легенд почвенных карт. ФАО и МГУ, 2018. 216 с.

10. Мягков М.С., Губернский Ю.Д., Конова Л.И., Лициевич В.К. Город, архитектура, человек и климат. Москва: «Архитектура-С», 2007. 344 с.

11. Попова И.В., Куролап С.А., Виноградов П.М. Моделирование «городского острова тепла» сред- ствами геоинформационного анализа // Жилищное хозяйство и коммунальная инфраструктура, 2018, № 2 (5), с. 87-95.

12. Рулев А.С., Шинкаренко С.С., Кошелева О.Ю. Оценка влияния гидрологического режима Волги на динамику затопления острова Сарпинский // Ученье записки Казанского университета. Серия: Естественные науки, 2017, т. 159, кн. 1, с. 139-151.

13. Специализированные массивы для климатических исследований. Доступно: http://aisori.meteo.ru/ ClimateR. (дата обращения: 15.01.2020).

14. Хромов С.П., Петросянц М. А. Метеорология и климатология. Москва: Изд-во МГУ, 2001. 528 с.

15. Chen J., Ban Y., Li S. China: Open access to Earth land-cover map // Nature, 2014, vol. 514 (7523), pp. 434. DOI: http://doi.org/10.1038/514434

16. Earthdata Search. Available at: https://search. earthdata.nasa.gov/. (accessed 21.01.2020).

17. Hu Y., Jia G., Pohl Ch., Feng Q., He Y., Gao H., Xu R., van Genderen J., Feng J. Improved monitoring of urbanization processes in China for regional climate impact assessment // Environmental Earth Sciences, 2015, v. 73, no 12, pp. 83878404. DOI: http://doi.org/10.1007/s12665-014-4000-4

Конфликт интересов: Авторы декларируют отсутствие явных и потенциальных конфликтов интересов, связанных с публикацией настоящей статьи.

Поступила в редакциюю 24.08.2020 Принята к публикации 02.03.202 


\title{
Daily and Seasonal Dynamics of Surface Temperature in the Volgograd City
}

\author{
O. Yu. Kosheleva ${ }^{1}$, S. S. Shinkarenko ${ }^{1,2}$, O. A. Gordienko ${ }^{1,2}$, \\ A. A. Dubacheva ${ }^{3}$, R. S. Omarov ${ }^{1,2}$ \\ ${ }^{1}$ FSC of Agroecology of the RAS, Russian Federation \\ (97, University Ave., Volgograd, 400062) \\ ${ }^{2}$ Volgograd State University, Russian Federation \\ (100, University Ave., Volgograd, 400062) \\ ${ }^{3}$ Russian Information and Analytical and Water Research Centre, Russian Federation \\ (6/1, Kanunnikov St., Volgograd, 400001)
}

\begin{abstract}
The research purpose is to reveal the features of daily and seasonal dynamics of surface temperature in the city of Volgograd (using the example of the year 2018, which was typical in terms of climatic characteristics) and to find out whether its seasonal course depends on characteristics of the underlying surface of the urban area.

Materials and methods. The choice of year for the study required analyzing a 20-year course of air temperatures in Volgograd. Availability of continuous data on temperatures of the underlying surface has also been taken into account. Determining the temperature of the urban surface has been carried out by processing images of the warm half of the year obtained using MOD11 A2 information product (8-day raster composites of day and night temperatures with a resolution of about $1 \mathrm{~km}$ ). Geo-informational processing of the images has been conducted in the QGIS program. Based on the Global Land Cover (GLC) data, the main types of underlying surface in the territory of Volgograd have been identified.

Results and discussion. The share of sealed soils makes 38,2\%. A map of average annual surface temperatures in Volgograd has been compiled. The map reflects the main features of spatial distribution of positive and negative thermal anomalies. It has been revealed that seasonal variation of the daily, daytime and nighttime average temperatures of the underlying surface and the surface air layer in Volgograd represents a parabola facing downward branches with a maximum falling on the period from June 26 to July 6 . The course of average daily air temperatures repeats the seasonal course of the city surface temperature $(\mathrm{r}=0,99)$.

Conclusions. Mapping based on MODIS data with a resolution of $1 \mathrm{~km}$ lets reveal the spatial distribution of large positive and negative anomalies in the city and its environs. The significant variability in the values of average daily temperature of the underlying surface in the areas with a high proportion of water bodies, wetlands and a low degree of soil coverage has been revealed.

Key words: surface heat area, MODIS, Volgograd, average daily temperature, daytime temperature of the urban surface, nighttime temperature of the urban surface, sealed soils.

Funding: The reported study was funded by RFBR and Volgograd region administration, project number 19-45-343001.

For citation: Kosheleva O.Yu., Shinkarenko S.S., Gordienko O.A., Dubacheva A.A., Omarov R.S. Daily and Seasonal Dynamics of Surface Temperature in the Volgograd City. Vestnik Voronezskogo gosudarstvennogo universiteta. Seria: Geografia. Geoekologia, 2021, no. 1, pp. 14-24. (In Russ.) DOI: https://doi.org/10.17308/geo.2021.1/3252
\end{abstract}

(C) Kosheleva O. Yu., Shinkarenko S. S., Gordienko O.A., Dubacheva A.A., Omarov R. S., 2021

$\varangle$ Olga Yu. Kosheleva, e-mail: olya_ber@mail.ru

The content is available under Creative Commons Attribution 4.0 License. 


\section{REFERENCES}

1. Baldina E.A., Grishchenko M.Yu., Konstantinov P.I., Varentsov M.I. Issledovanie gorodskikh ostrovov tepla s pomoshch'yu dannykh distantsion-nogo zondirovaniya $\mathrm{v}$ infrakrasnom teplovom diapazone [Study of urban heat Islands using remote sensing data in the infrared thermal range]. Zemlya iz kosmosa - naibolee effektivnye resheniya, 2015, spetsial'nyy vypusk, pp. 38-42. (In Russ.)

2. Brusova N.E., Kuznetsova I.N., Nakhaev M.I. Teplovoe vozmushchenie megapolisa na fone regional'noy neodnorodnosti polya prizemnoy temperatury [Thermal disturbance in the megapolis on the background of the regional surface air temperature variability]. Trudy Gidromettsentra Rossii, 2017, v. 365, pp. 22-34. (In Russ.)

3. Gordienko O.A., Manaenkov I. V., Kholodenko A. V., Ivantsova E.A. Kartografirovanie i otsenka stepeni zapechatannosti pochv goroda Volgograda [Mappingof soils and assessment of sealed areas in the city of Volgograd]. Pochvovedenie, 2019, no 11, pp. 1383-1392. (In Russ.) DOI: http://doi.org/10.1134/S0032180X19110054

4. Grishchenko M.Yu., Kalitka L. S. Izuchenie sezonnoy izmenchivosti teplovogo polya Krasnodara po kosmicheskim snimkam so sputnika Landsat 8 [Studying the seasonal variability of thermal field of Krasnodar using Landsat 8 satellite imagery]. Materialy Mezhdunarodnaya konferentsiya «InterKarto. InterGIS. Geo-informatsionnoe obespechenie ustoychivogo razvitiya territoriy». Moscow, 2019, vol. 25, part 2, pp. 101-111. (In Russ.) DOI: http:// doi.org/10.35595/2414-9179-2019-2-25-101-111

5. Ermakova E.V., Martynenko I.A. Otsenka vliyaniya zapechatannosti poverkhnosti pochvennogo pokrova na raspredelenie temperatury poverkhnosti $\mathrm{v}$ usloviyakh goroda na primere yugo-vostochnogo okruga g. Moskvy [Eestimation of influence of sealing of the soil surface on the surface temperature distribution in the city as an example South-East district of Moscow]. Vestnik Orenburgskogo gosudarstvennogo universiteta, 2011, no 12 (131), pp. 68-70. (In Russ.)

6. Kosheleva O.Yu. Otsenka zapechatannosti pochvennogo pokrova goro-da Volgograda [Assessment of the sealing of the soil cover of the city of Volgograd]. Vestnik Voronezhskogo gosudarstvennogo universiteta. Seria: Geografia. Geoekologia, 2019, no 1, pp. 12-18. (In Russ.) DOI: https://doi.org/10.17308/geo.2019.1/2280

7. Kritsuk S.G., Gornyy V.I., Latypov I.Sh., Pavlovskiy A.A., Tronin A.A. Sputnikovoe kartirovanie riska peregreva poverkhnosti gorodskoy sredy (na primere Sankt-Peterburga) [Satellite risk mapping of urban surface overheating (by the example of Saint Petersburg)]. Sovremennye problemy distantsionnogo zondirovaniya Zemli iz kosmosa, 2019, vol. 16, no 5, pp. 34-44. (In Russ.) DOI: http://doi.org/10.21046/2070-7401-2019-16-5-34-44

8. Litvinov D. V. Printsipy zonirovaniya pribrezhnykh territoriy $\mathrm{v}$ zavisimosti ot planirovochnoy struktury goroda (na primere gorodov Povolzh'ya) [Principles of zoning of coastal territories depending on planning structure of city (on the example of cities of the Volga region)]. Vestnik Samarskogo gosudarstvennogo arkhitekturno-stroitel'nogo universiteta. Gradostroitel'stvo $i$ arkhitektura, 2011, no 3, pp. 32-34. (In Russ.) DOI: http://doi.org/10.17673/ Vestnik.2011.03.8

9. Mirovaya referativnaya baza pochvennykh resursov 2014. Mezhduna-rodnaya sistema pochvennoy klassifikatsii dlya diagnostiki pochv i sozdaniya legend pochvennykh kart [World Reference Base for Soil Resources 2014. International soil classification system for naming soils and creating legends for soil maps]. FAO i MGU, 2018, 216 p. (In Russ.)

10. Myagkov M.S., Gubernskiy Yu. D., Konova L.I., Litsievich V.K. Gorod, arkhitektura, chelovek $i$ klimat [City, architecture, people and climate]. Moscow: «Arkhitektura-S», 2007. 344 p. (In Russ.)

11. Popova I.V., Kurolap S.A., Vinogradov P.M. Modelirovanie «gorodskogo ostrova tepla» sredstvami geoinformatsionnogo analiza [Modeling «urban heat islands» by tools of GIS-analysis]. Zhilishchnoe khozyaystvo i kommunal'naya infrastruktura, 2018, no 2 (5), pp. 87-95. (In Russ.)

12. Rulev A.S., Shinkarenko S.S., Kosheleva O.Yu. Otsenka vliyaniya gidrologicheskogo rezhima Volgi na dinamiku zatopleniya ostrova Sarpinskiy [Assessment of influence of hydrological regime of the Volga on dynamics of flooding on Sarpinsky island]. Uchenye zapiski Kazanskogo universiteta. Seria: Estestvennye nauki, 2017, vol. 159, b. 1, pp. 139-151. (In Russ.)

13. Spetsializirovannye massivy dlya klimaticheskikh issledovaniy [Specialized arrays for climate research]. Available at: http://aisori.meteo.ru/ClimateR. (accessed 15.01.2020). (In Russ.)

14. Khromov C.P., Petrosyants M.A. Meteorologiya i klimatologiya [Meteorology and climatology]. Moscow: Izd-vo MGU, 2001. 528 p. (In Russ.)

15. Chen J., Ban Y., Li S. China: Open access to Earth land-cover map. Nature, 2014, v. 514 (7523), pp. 434. DOI: http://doi.org/10.1038/514434

16. Earthdata Search. Available at: https://search. earthdata.nasa.gov/. (accessed 21.01.2020).

17. Hu Y., Jia G., Pohl Ch., Feng Q., He Y., Gao H., $\mathrm{Xu}$ R., van Genderen J., Feng J. Improved monitoring of urbanization processes in China for regional climate impact assessment. Environmental Earth Sciences, 2015, v. 73, no 12 , pp. 8387-8404. DOI: http://doi.org/10.1007/ s12665-014-4000-4

Conflict of interest: The authors declare no information of obvious and potential conflicts of interest related to the publication of this article.

Received 24.08.2020 Accepted 02.03.2021 
Кошелева Ольга Юрьевна

кандидат сельскохозяйственных наук, старший научный сотрудник лаборатории геоинформационного моделирования и картографирования агролесоландшафтов ФГБНУ «Федеральный научный центр агроэкологии, комплексных мелиораций и защитного лесоразведения Российской академии наук», г. Волгоград, Российская Федерация, ORCID: 0000-0002-9616-2383, e-mail: olya ber@mail.ru

\section{Шинкаренко Станислав Сергеевич}

кандидат сельскохозяйственных наук, научный сотрудник лаборатории геоинформационного моделирования и картографирования агролесоландшафтов ФГБНУ «Федеральный научный центр агроэкологии, комплексных мелиораций и защитного лесоразведения Российской академии наук»; доцент кафедры «География и картография» Волгоградского государственного университета, г. Волгоград, Российская Федерация, ORCID: 0000-0002-9269-4489, e-mail: shinkarenkos@ vfanc.ru

Гордиенко Олег Андреевич

младший научный сотрудник лаборатории защиты почв от эрозии ФГБНУ «Федеральный научный центр агроэкологии, комплексных мелиораций и защитного лесоразведения Российской академии наук»; аспирант кафедры экологии и природопользования Волгоградского государственного университета, г. Волгоград, Российская Федерация, ORCID: 0000-0001-5381-9114, e-mail: gordienko-o@vfanc.ru

\section{Дубачева Анастасия Алексеевна}

ведущий инженер отдела обеспечения ведения государственного водного реестра (ГВР) и АИС ГВР ФГБУ «Российский информационно-аналитический и научно-исследовательский водохозяйственный центр», г. Волгоград, Российская Федерация, ORCID: 0000-00033279-1460, e-mail: dubatcheva.a@gmail.com

\section{Омаров Роман Сергеевич}

лаборант-исследователь лаборатории геоинформационного моделирования и картографирования агролесоландшафтов ФГБНУ «Федеральный научный центр агроэкологии, комплексных мелиораций и защитного лесоразведения Российской академии наук», магистрант кафедры «География и картография» Волгоградского государственного университета, г. Волгоград, Российская Федерация, ORCID: 0000-0003-27623673, e-mail: omarov-r@vfanc.ru
Olga Yu. Kosheleva

Cand. Sci. (Agriculture), Senior Researcher of the Laboratory of geoinformation modelling and agroforest landscapes mapping of the Federal State Budget Scientific Institution «Federal Scientific Centre of Agroecology, Complex Melioration and Protective Afforestation of the Russian Academy of Sciences» (FSC of Agroecology RAS), Volgograd, Russian Federation, ORCID: 0000-0002-96162383, e-mail: olya_ber@mail.ru

Stanislav S. Shinkarenko

Cand. Sci. (Agriculture), Researcher of the Laboratory of geoinformation modelling and agroforest landscapes mapping of the Federal State Budget Scientific Institution «Federal Scientific Center of Agroecology, Complex Melioration and Protective Afforestation of the Russian Academy of Sciences» (FSC of Agroecology RAS); Associate Professor at the Department of Geography and Cartography of the Volgograd State University, Volgograd, Russian Federation, ORCID: 0000-0002-9269-4489, e-mail: shinkarenkos@vfanc.ru

Oleg A. Gordienko

Junior Researcher of the Laboratory of soil protection from erosion of the Federal State Budget Scientific Institution «Federal Scientific Centre of Agroecology, Complex Melioration and Protective Afforestation of the Russian Academy of Sciences» (FSC of Agroecology RAS); Postgraduate Student of the Department of Ecology and Environment Management of the Volgograd State University, Volgograd, Russian Federation, ORCID: 0000-0001-53819114, e-mail: gordienko-o@vfanc.ru

Anastasiya A. Dubacheva

Lead Engineer of the Department of state water register maintenance and automated information system of the state water register of the Federal State Budgetary Institution «Russian Information and Analytical and Water Research Centre», Volgograd, Russian Federation, ORCID: 0000-0003-3279-1460, e-mail: dubatcheva.a@gmail.com

Roman S. Omarov

Research assistant of the Laboratory of geoinformation modelling and agroforest landscapes mapping of the Federal State Budget Scientific Institution «Federal Scientific Centre of Agroecology, Complex Melioration and Protective Afforestation of the Russian Academy of Sciences» (FSC of Agroecology RAS); Master's Student of the Department of Geography and Cartography of the Volgograd State University, Volgograd, Russian Federation, ORCID: 0000-0003-2762-3673, e-mail: omarov-r@vfanc.ru 